TITLE:

\title{
Mechanism and bounding of earthquake energy input to building structure on surface ground subjected to engineering bedrock motion
}

\section{$\operatorname{AUTHOR}(\mathrm{S}):$}

Kojima, K.; Sakaguchi, K.; Takewaki, I.

\section{CITATION:}

Kojima, K.... [et al]. Mechanism and bounding of earthquake energy input to building structure on surface ground subjected to engineering bedrock motion. Soil Dynamics and Earthquake Engineering 2015, 70: 93-103

\section{ISSUE DATE:}

2015-03

URL:

http://hdl.handle.net/2433/193666

\section{RIGHT:}

(C) 2014 Elsevier Ltd.; This is not the published version. Please cite only the published version.; この論文は出版社版でありません。引用の際に は出版社版をご確認ご利用ください。 


\title{
Mechanism and bounding of earthquake energy input to building structure on surface ground subjected to engineering bedrock motion
}

\author{
K. Kojima, K. Sakaguchi, I. Takewaki* \\ Department of Architecture and Architectural Engineering, \\ Graduate School of Engineering, Kyoto University, \\ Kyotodaigaku-Katsura, Nishikyo, Kyoto 615-8540, Japan
}

\begin{abstract}
The mechanism of earthquake energy input to building structures is clarified by considering the surface ground amplification and soil-structure interaction. The earthquake input energies to superstructures, soil-foundation systems and total swaying-rocking system are obtained by taking the corresponding appropriate free bodies into account and defining the energy transfer functions. It has been made clear that, when the ground surface motion is white, the input energy to the swaying-rocking model is constant regardless of the soil property (input energy constant property). The upper bound of earthquake input energy to the swaying-rocking model is derived for the model including the surface ground amplification by taking full advantage of the above-mentioned input energy constant property and introducing the envelope function for the transfer function of the surface ground amplification. Extension of the theory to a general earthquake ground motion model at the engineering bedrock is also made by taking full advantage of the above-mentioned input energy constant property.
\end{abstract}

Keywords: Earthquake input energy, Energy transfer function, Swaying-rocking model, Soil-structure interaction, Surface ground amplification, Upper bound of input energy

*Corresponding author: E-mail, takewaki@archi.kyoto-u.ac.jp 


\section{Introduction}

In the history of seismic resistant design of building structures, the earthquake input energy has been getting much interest together with deformation and acceleration. While deformation and acceleration can predict and evaluate the performance of a structure mainly for serviceability, the energy can evaluate the performance of a structure mainly for safety. Especially energy is appropriate for describing the performance of structures of different sizes in a unified manner because energy is a global index different from deformation and acceleration as local indices. Furthermore it has been understood well [1-3] that energy is suitable for soil-structure interaction problems because this problem can be expressed reasonably by considering the exchange of energy between structures and soil.

Much work has been accumulated so far on the topics of earthquake input energy (for example, [4-15]). However the earthquake input energy to soil-structure systems has not been thoroughly considered in literature. This is because the behavior of a soil-structure system is quite complicated and its frequency-dependent characteristics are difficult to incorporate in the time-history analysis for computation of input energy. In contrast to most of the previous works, the earthquake input energy is formulated here in the frequency domain $[3,16-21]$ to facilitate the derivation of bound of earthquake input energy which is useful for the design of building structures under uncertain soil conditions.

In order to clarify the energy dissipation mechanism in the soil-structure interaction system, three kinds of input energy are defined, one to the overall soil-structure interaction system, one to the superstructure only and the other to the foundation-soil system. The structures treated in this paper are restricted to elastic structures in order to make the formulation simple. The difference between these three energies indicates the energy dissipated in the soil or that radiating into the ground. It is demonstrated that the input energy expressions for the above-mentioned three systems or substructures can be of a compact form via the frequency integration of the product between the input component (Fourier amplitude spectrum) and the substructure model component (so-called energy transfer function). With the help of this compact form, it will be made clear that, when the ground surface motion is white, the input energy to the swaying-rocking model is constant regardless of the soil 
property (input energy constant property). The upper bound of earthquake input energy to the swaying-rocking model is then derived for the model including the surface ground amplification by taking full advantage of the above-mentioned input energy constant property and introducing the envelope function for the transfer function of the surface ground amplification. Extension of the theory to a general earthquake ground motion model at the engineering bedrock will also be made by taking full advantage of the above-mentioned input energy constant property.

\section{Earthquake input energy to overall SR model subjected to free-field ground motion}

Consider a one-story shear building model (mass $m$, stiffness $k$, damping coefficient $c)$, as shown in Fig.1, supported by swaying and rocking springs $k_{H}, k_{R}$ and dashpots $c_{H}, c_{R}$. This model is called the SR (Swaying-Rocking) model. Let $m_{0}, I_{R 0}, L$ denote the foundation mass, its mass moment of inertia and the height of the structural mass from the base. The moment of inertia of structural mass is $I_{R}$. This model is subjected to a horizontal acceleration $\ddot{u}_{g}(t)$ at the free-field ground surface. Let $u_{S}, \theta_{R}$ denote the foundation horizontal displacement and its angle of rotation. The horizontal displacement of the supermass relative to the foundation without rocking component is denoted by $u$.

The equations of motion of the model may be expressed as

$$
\mathbf{M u ̈}+\mathbf{C u}+\mathbf{K u}=-\mathbf{M r} \ddot{u}_{g}
$$

where

$$
\begin{aligned}
& \mathbf{M}=\left[\begin{array}{ccc}
m & m & L m \\
m & m_{0}+m & L m \\
L m & L m & L^{2} m+I_{R}+I_{R 0}
\end{array}\right], \\
& \mathbf{K}=\operatorname{diag}\left(\begin{array}{lll}
k & k_{H} & k_{R}
\end{array}\right), \\
& \mathbf{C}=\operatorname{diag}\left(\begin{array}{lll}
c & c_{H} & c_{R}
\end{array}\right) \quad(\text { structural damping and soil damping }) \\
& \mathbf{u}=\left(\begin{array}{llll}
u & u_{S} & \theta_{R}
\end{array}\right)^{T}, \mathbf{r}=\left(\begin{array}{lll}
0 & 1 & 0
\end{array}\right)^{T}
\end{aligned}
$$

Let us introduce the absolute horizontal displacement $y$ of the super-mass as 


$$
y=u+u_{S}+L \theta_{R}
$$

Considering the free-body diagram as shown in Fig.2, the earthquake input energy to the SR model under the free-field horizontal ground acceleration $\ddot{u}_{g}$ may be expressed as

$$
E_{I}^{A}=\int_{0}^{\infty}\left\{-\left(k_{H} u_{S}+c_{H} \dot{u}_{S}\right)\right\} \dot{u}_{g} d t
$$

This is the work done by the boundary force on the boundary displacement. The force equilibrium of the free body in Fig.2 provides

$$
\left\{-\left(k_{H} u_{S}+c_{H} \dot{u}_{S}\right)\right\}=m_{0}\left(\ddot{u}_{S}+\ddot{u}_{g}\right)+m\left(\ddot{y}+\ddot{u}_{g}\right)
$$

Substitution of Eq.(5) into Eq.(4) leads to

$$
E_{I}^{A}=\int_{0}^{\infty}\left\{m_{0}\left(\ddot{u}_{S}+\ddot{u}_{g}\right)+m\left(\ddot{y}+\ddot{u}_{g}\right)\right\} \dot{u}_{g} d t
$$

Premultiplication of $\dot{\mathbf{u}}^{T}$ on Eq.(1) and integration of the resulting equation from time $=0$ to $t_{0}$ lead to

$$
\int_{0}^{\infty} \dot{\mathbf{u}}^{T}\{\mathbf{M} \ddot{\mathbf{u}}+\mathbf{C} \dot{\mathbf{u}}+\mathbf{K u}\} d t=-\int_{0}^{\infty} \dot{\mathbf{u}}^{T} \mathbf{M r} \ddot{u}_{g} d t
$$

Integration by parts of the right-hand side of Eq.(7) and its rearrangement by use of $\dot{u}_{g}(0)=\dot{u}_{g}\left(t_{0}\right)=0$ provide

$$
-\int_{0}^{\infty} \dot{\mathbf{u}}^{T} \mathbf{M r} \ddot{u}_{g} d t=-\left[\dot{\mathbf{u}}^{T} \mathbf{M r} \dot{u}_{g}\right]_{0}^{\infty}+\int_{0}^{\infty} \dot{\mathbf{i}}^{T} \mathbf{M r} \dot{u}_{g} d t=\int_{0}^{\infty}\left\{m_{0}\left(\ddot{u}_{S}+\ddot{u}_{g}\right)+m\left(\ddot{y}+\ddot{u}_{g}\right)\right\} \dot{u}_{g} d t
$$

From Eqs.(6) and (8), the earthquake input energy to the SR model may be expressed finally as

$$
E_{I}^{A}=-\int_{0}^{\infty} \dot{\mathbf{u}}^{T} \mathbf{M r} \ddot{u}_{g} d t
$$

It is known that, in linear elastic structures, the earthquake input energy can also be expressed in the frequency domain [10, 17-21]. Let $U, U_{S}, \Theta_{R}, Y, U_{g}$ denote the Fourier transforms of $u, u_{S}, \theta_{R}, y, u_{g}$ and $H, H_{S}, H_{R}, H_{Y}$ denote the transfer functions of $u, u_{S}, \theta_{R}, y$ to $\ddot{u}_{g}$ as follows. 


$$
U / \ddot{U}_{g}=H(\omega), U_{S} / \ddot{U}_{g}=H_{S}(\omega), \Theta_{R} / \ddot{U}_{g}=H_{R}(\omega), Y / \ddot{U}_{g}=H_{Y}(\omega)
$$

Extension of the upper and lower integration limits in Eq.(6) into $\infty,-\infty$ using the property of $\dot{u}_{g}$ as $\dot{u}_{g}=0$ for $t<0$ and application of Fourier transformation with expressions of Eq.(10) lead to

$$
\begin{aligned}
E_{I}^{A} & =\frac{1}{2 \pi} \int_{-\infty}^{\infty} \int_{-\infty}^{\infty}\left\{m_{0}\left(\ddot{U}_{S}+\ddot{U}_{g}\right)+m\left(\ddot{Y}+\ddot{U}_{g}\right)\right\} \dot{u}_{g} e^{\mathrm{i} \omega t} d t d \omega \\
& =\int_{0}^{\infty} \frac{1}{\pi} \operatorname{Re}\left[\frac{1}{i \omega}\left\{m_{0}\left(\omega^{2} H_{S}-1\right)+m\left(\omega^{2} H_{Y}-1\right)\right\}\right]\left|\ddot{U}_{g}\right|^{2} d \omega
\end{aligned}
$$

In this paper, ()$^{*}$ denotes the complex conjugate, $\operatorname{Re}[$ ] indicates the real part of a complex number and i denotes the imaginary unit. The frequency-domain expression in Eq.(11) may also be possible with the matrix expression of Eq.(9).

$$
E_{I}^{A}=-\frac{1}{2 \pi} \int_{-\infty}^{\infty} \int_{-\infty}^{\infty} \dot{\mathbf{U}}^{T} \mathbf{M r} \ddot{u}_{g} e^{\mathrm{i} \omega t} d t d \omega=\int_{0}^{\infty}\left\{-\frac{1}{\pi} \operatorname{Re}\left[i \omega \mathbf{H}^{T} \mathbf{M r}\right]\right\}\left|\ddot{U}_{g}\right|^{2} d \omega
$$

where

$$
\mathbf{H}=\left\{\begin{array}{lll}
H & H_{S} & H_{R}
\end{array}\right\}^{T}
$$

Eqs.(11) and (12) can be expressed in a compact form as

$$
E_{I}^{A}=\int_{0}^{\infty} F_{A}(\omega)\left|\ddot{U}_{g}\right|^{2} d \omega
$$

where $F_{A}(\omega)$ is called the energy transfer function of the SR model and is expressed by

$$
\begin{aligned}
& F_{A}(\omega)=\frac{1}{\pi} \operatorname{Re}\left[\frac{1}{i \omega}\left\{m_{0}\left(\omega^{2} H_{S}-1\right)+m\left(\omega^{2} H_{Y}-1\right)\right\}\right] \\
& F_{A}(\omega)=-\frac{1}{\pi} \operatorname{Re}\left[i \omega \mathbf{H}^{T} \mathbf{M r}\right]
\end{aligned}
$$

\section{Earthquake input energy to substructures in SR model}

\subsection{Earthquake input energy to superstructure}

Consider the free-body diagram for the superstructure as shown in Fig.3. The earthquake input energy to the superstructure can be expressed as 


$$
E_{I}^{S}=\int_{0}^{\infty}\{-(k u+c \dot{u})\}\left(\dot{u}_{S}+\dot{u}_{g}\right) d t+\int_{0}^{\infty}\left[m L\left(\ddot{y}+\ddot{u}_{g}\right)+I_{R} \ddot{\theta}_{R}\right] \dot{\theta}_{R} d t
$$

Application of Fourier inverse transformation and Fourier transformation to Eq.(16) and use of Eq.(10) provide

$$
\begin{aligned}
E_{I}^{S} & =\int_{0}^{\infty} \frac{1}{\pi} \operatorname{Re}\left[(k+i \omega c) H\left(i \omega H_{S}{ }^{*}+\frac{1}{i \omega}\right)\right]\left|\ddot{U}_{g}\right|^{2} d \omega \\
& +\int_{0}^{\infty} \frac{1}{\pi} \operatorname{Re}\left[i \omega\left\{m L\left(\omega^{2} H_{Y}-1\right)+\omega^{2} I_{R} H_{R}\right\} H_{R}{ }^{*}\right]\left|\ddot{U}_{g}\right|^{2} d \omega
\end{aligned}
$$

Eq.(17) can be expressed compactly as

$$
E_{I}^{S}=\int_{0}^{\infty} F_{S}(\omega)\left|\ddot{U}_{g}\right|^{2} d \omega
$$

where

$$
F_{S}(\omega)=\frac{1}{\pi} \operatorname{Re}\left[(k+i \omega c) H\left(i \omega H_{S}{ }^{*}+\frac{1}{i \omega}\right)+i \omega\left\{m L\left(\omega^{2} H_{Y}-1\right)+\omega^{2} I_{R} H_{R}\right\} H_{R}{ }^{*}\right]
$$

\subsection{Earthquake input energy to foundation-soil system}

Consider the free-body diagram for the foundation-soil system as shown in Fig.4. The earthquake input energy to the foundation-soil system can be expressed as

$$
E_{I}^{F}=\int_{0}^{\infty}\left\{-\left(k_{H} u_{S}+c_{H} \dot{u}_{S}\right)\right\} \dot{u}_{g} d t+\int_{0}^{\infty}(k u+c \dot{u})\left(\dot{u}_{S}+\dot{u}_{g}\right) d t-\int_{0}^{\infty}\left[m L\left(\ddot{y}+\ddot{u}_{g}\right)+I_{R} \ddot{\theta}_{R}\right] \dot{\theta}_{R} d t
$$

From Eqs.(4), (16), (20), the following relation holds among the earthquake input energies to the substructures and the overall system.

$$
E_{I}^{F}=E_{I}^{A}-E_{I}^{S}
$$

By substituting Eqs.(11) and (17) into Eq.(21), the earthquake input energy to the foundationsoil system can also be expressed in the frequency domain as

$$
\begin{aligned}
E_{I}^{F}= & \int_{0}^{\infty} \frac{1}{\pi} \operatorname{Re}\left[\frac{1}{i \omega}\left[m_{0}\left(\omega^{2} H_{S}-1\right)+m\left(\omega^{2} H_{Y}-1\right)\right]\right]\left|\ddot{U}_{g}\right|^{2} d \omega \\
& -\int_{0}^{\infty} \frac{1}{\pi} \operatorname{Re}\left[(k+i \omega c) H\left(i \omega H_{S}{ }^{*}+\frac{1}{i \omega}\right)\right]\left|\ddot{U}_{g}\right|^{2} d \omega \\
& -\int_{0}^{\infty} \frac{1}{\pi} \operatorname{Re}\left[i \omega\left\{m L\left(\omega^{2} H_{Y}-1\right)+\omega^{2} I_{R} H_{R}\right\} H_{R}{ }^{*}\right]\left|\ddot{U}_{g}\right|^{2} d \omega
\end{aligned}
$$


Eq.(22) can be expressed compactly as

$$
E_{I}^{F}=\int_{0}^{\infty} F_{F}(\omega)\left|\ddot{U}_{g}\right|^{2} d \omega
$$

where

$$
F_{F}(\omega)=\frac{1}{\pi} \operatorname{Re}\left[\begin{array}{l}
\frac{1}{i \omega}\left\{m_{0}\left(\omega^{2} H_{S}-1\right)+m\left(\omega^{2} H_{Y}-1\right)\right\} \\
-(k+i \omega c) H\left(i \omega H_{S}{ }^{*}+\frac{1}{i \omega}\right) \\
-i \omega\left\{m L\left(\omega^{2} H_{Y}-1\right)+\omega^{2} I_{R} H_{R}\right\} H_{R}{ }^{*}
\end{array}\right]
$$

\section{Property of earthquake input energy to overall SR model subjected to white-noise-like}

\section{free-field input}

Consider the earthquake input energy to the overall SR model subjected to a whitenoise-like free-field input with $\left|\ddot{U}_{g}(\omega)\right|=1$. This quantity is called the 'scaled earthquake input energy' for the free-field input and can be evaluated by

$$
J_{S R}^{F}=\int_{0}^{\infty} F_{A}(\omega) d \omega=\frac{1}{2} \sum m_{i}
$$

The summation is extended to the superstructure masses and the foundation mass. Eq.(25) can be proved by taking into account that a white-noise-like free-field input with $\left|\ddot{U}_{g}(\omega)\right|=1$ is equivalent to the impulsive loading with the initial velocity of 1 in time domain [21].

\section{Earthquake input energy to overall SR model subjected to engineering bedrock input}

Consider a uniform surface ground on uniform engineering bedrock. If we deal with the ground motion propagation from the earthquake bedrock (around $1 \mathrm{~km}-2 \mathrm{~km}$ ) to the engineering bedrock, two or three dimensional treatment may be appropriate. However, the present paper deals with the input from the engineering bedrock. It is well known that the earthquake ground motion input can be treated in most cases as a vertical propagating one after the propagation in multiple layers due to the Snell's law. Furthermore, because the main purpose of this paper is to provide a new method for evaluating the upper bound of input 
energy to a building structure on a surface ground, a simple but fundamental situation is assumed. Once the transfer function between a position at underground and the free-field ground surface is provided, a similar method can be developed without difficulty.

Let $\rho_{1}, V_{S 1}, G_{1}, \beta_{1}$ and $h_{1}$ denote the mass density, the shear wave velocity, the shear modulus, the damping ratio and the depth of the surface ground. The mass density and shear wave velocity of the engineering bedrock are denoted by $\rho_{2}$ and $V_{S 2}$. The absolute value of the transfer function of the free-field surface ground motion $2 E_{1}$ to the outcropping engineering bedrock surface ground motion $2 E_{2}$ can be expressed [22, 23] by

$$
\left|\frac{2 E_{1}}{2 E_{2}}\right|=\left|H_{G}(\omega)\right|=\frac{1}{\sqrt{\cos ^{2} k_{1} h_{1}+\alpha^{2} \sin ^{2} k_{1} h_{1}}}
$$

where

$$
k_{1} h_{1}=\sqrt{\frac{\rho_{1}}{G_{1}}} h_{1} \omega=\frac{h_{1}}{V_{S 1}} \omega, \quad \alpha=\left(\rho_{1} V_{S 1} /\left(\rho_{2} V_{S 2}\right)\right)
$$

For the damped case, $k_{1} h_{1}$ in Eq.(26) can be expressed by

$$
k_{1} h_{1}=\sqrt{\frac{\rho_{1}}{G_{1}^{+}}} h_{1} \omega=\frac{h_{1}}{{V_{S 1}}^{+}} \omega, G_{1}^{+}=\left(1+2 \beta_{1} \mathrm{i}\right) G_{1}, V_{S 1}^{+}=\sqrt{G_{1}^{+} / \rho_{1}}
$$

With the help of Eq.(26), the free-field surface ground acceleration $\ddot{U}_{g}(\omega)$ in the frequency domain may be related to the outcropping engineering bedrock surface ground acceleration $\ddot{U}_{g 0}(\omega)$ through

$$
\ddot{U}_{g}(\omega)=H_{G}(\omega) \ddot{U}_{g 0}(\omega)
$$

Substitution of Eq.(29) into Eq.(14) leads to

$$
E_{I}^{A}=\int_{0}^{\infty} F_{A}(\omega)\left|H_{G}(\omega)\right|^{2}\left|\ddot{U}_{g 0}(\omega)\right|^{2} d \omega
$$

Define the following quantity.

$$
J_{S R}=\int_{0}^{\infty} F_{A}(\omega)\left|H_{G}(\omega)\right|^{2} d \omega
$$

$J_{S R}$ in Eq.(31) indicates the earthquake input energy to the overall SR model subjected to a 
white-noise-like engineering bedrock input with $\left|\ddot{U}_{g 0}(\omega)\right|=1$. The quantity is called later the 'scaled earthquake input energy' for the engineering bedrock input. It should be noted that, while one-layer surface ground has been treated in this section for simple presentation of $H_{G}(\omega)$, the general form of $H_{G}(\omega)$ for multi-layered ground [22, 23] can be used in the following sections without difficulty. Furthermore extension of the theory developed in the following section to a more general earthquake ground motion model with varied Fourier spectrum will be presented in Section 8 .

\section{Upper bound of earthquake input energy to overall SR model subjected to white- noise-like engineering bedrock input}

\subsection{Case of undamped surface ground amplification}

Uncertainties exist in the surface ground amplification due to geometrical and geotechnical irregularity and non-uniformity. It is therefore meaningful to discuss the upper bound of the earthquake input energy to the SR model.

Consider the bounds of the scaled earthquake input energy for the engineering bedrock input defined by Eq.(31). Since the energy transfer function $F_{A}(\omega)$ in Eq.(31) is usually positive, it is sufficient to discuss the envelope function of $\left|H_{G}(\omega)\right|^{2}$.

Consider first the undamped case for the free-field ground amplification. Fig.5 shows an example of the energy transfer function $F_{A}(\omega)$ and an example of the function $\left|H_{G}(\omega)\right|^{2}$. Let $J_{S R}^{U}, J_{S R}^{L}$ and $\hat{J}_{S R}$ denote the upper bound, lower bound and proposed upper bound using a narrower bound of amplification (see Fig.5). Furthermore let $U_{b}$ and $L_{b}$ denote the upper bound and lower bound of the squared transfer function of the surface ground (see Fig.5). $J_{S R}^{U}, J_{S R}^{L}$ and $\hat{J}_{S R}$ can be derived as follows:

$$
\begin{aligned}
& J_{S R}^{U}=\frac{1}{2} U_{b} \sum m_{i} \\
& J_{S R}^{L}=\frac{1}{2} L_{b} \sum m_{i}
\end{aligned}
$$




$$
\begin{aligned}
J_{S R} & =\int_{0}^{\omega_{U}} F_{A}(\omega)\left[U_{b}-\left\{U_{b}-\left|H_{G}(\omega)\right|^{2}\right\}\right] d \omega+\int_{\omega_{U}}^{\infty} F_{A}(\omega) \underline{\left|H_{G}(\omega)\right|^{2}} d \omega \\
& \leq \int_{0}^{\omega_{U}} F_{A}(\omega)\left[U_{b}-\left\{U_{b}-\left|H_{G}(\omega)\right|^{2}\right\}\right] d \omega+\int_{\omega_{U}}^{\infty} F_{A}(\omega) \underline{U_{b}} d \omega \\
& =U_{b} \int_{0}^{\infty} F_{A}(\omega) d \omega-\int_{0}^{\omega_{U}} F_{A}(\omega)\left\{U_{b}-\left|H_{G}(\omega)\right|^{2}\right\} d \omega \\
& =\frac{1}{2} U_{b} \sum m_{i}-\int_{0}^{\omega_{U}} F_{A}(\omega)\left\{U_{b}-\left|H_{G}(\omega)\right|^{2}\right\} d \omega=\hat{J}_{S R}
\end{aligned}
$$

In Eq.(32c), $\omega_{U}$ denotes the upper limit of circular frequency for computation shown in Fig.5. The validity of inequality in Eq.(32c) can be proven by the property of $F_{A}(\omega)$ as a positive function. The positivity of $F_{A}(\omega)$ can be shown from the fact that, if some parts of $F_{A}(\omega)$ are negative, it contradicts the positivity of the energy consumption (total input energy) in the SR model subjected to an infinitely long sinusoidal ground motion expressed by a Dirac delta function at the corresponding frequency. Eq.(32c) enables the evaluation of the upper bound of the scaled earthquake input energy without infinite integration by taking full advantage of Eq.(25).

Consider three soil types 1-3 as shown in Fig.6. The shear wave velocities $V_{S}$ of the surface ground for these three soil types $1-3$ are set as $200(\mathrm{~m} / \mathrm{s}), 133(\mathrm{~m} / \mathrm{s})$ and $100(\mathrm{~m} / \mathrm{s})$. The thickness of the surface ground is $20(\mathrm{~m})$. These shear wave velocities correspond to the natural period of $0.4,0.6,0.8(\mathrm{~s})$. The shear wave velocity of the engineering bedrock is $400(\mathrm{~m} / \mathrm{s})$. The mass density of the engineering bedrock is assumed to be the same as that of the surface ground for simplicity.

The superstructure is modeled as a five-story shear building model and each floor mass is $51,200(\mathrm{~kg})$. The equal story height is $3.5(\mathrm{~m})$. The superstructure is transformed into a single-degree-of-freedom model by assuming a triangular lowest mode for a fixed-base model. The determined parameters are shown in Table 1.

The swaying and rocking stiffnesses and damping coefficients are computed by the following simple formulae [24].

$$
\begin{aligned}
& k_{H}=(6.77 /(1.97-v)) G r, k_{R}=(2.52 /(1.00-v)) G r^{3} \\
& c_{H}=(6.21 /(2.54-v)) \rho V_{S} r^{2}, c_{R}=(0.136 /(1.13-v)) \rho V_{S} r^{4}
\end{aligned}
$$

The mass density of the surface ground is $\rho=1.8 \times 10^{3}$ and that of the engineering bedrock is 
assumed to be the same for simplicity. The mass densities of hard ground and soft ground are not so different actually and a slight variation of mass density does not affect the response result so much. The shear modulus of the surface ground is given by $G=\rho V_{S}^{2}$. Poisson's ratio of the surface ground is $v=0.35$. The radius of the foundation is $r=4(\mathrm{~m})$. Although a set of simple frequency-independent coefficients is used here, more complicated frequencydependent coefficients can be employed without difficulty owing to the frequency formulation in this paper.

Fig.7 shows $J_{S R}^{U}, J_{S R}^{L}, \hat{J}_{S R}$ and the actual one with respect to the ratio of the fundamental natural circular frequency $\omega_{1}$ of the superstructure to the fundamental natural circular frequency $\omega_{G}$ of the surface ground for three soil types 1-3. 200(rad/s) was adopted as $\omega_{U}$ in Eq.(32c) and 5000(rad/s) was employed as the upper circular frequency for computation in Eq.(31). It can be observed that, as the surface ground becomes softer, the degree of overestimation by $J_{S R}^{U}$ becomes larger due to the increase of the impedance ratio. However the proposed upper bound of the scaled earthquake input energy $\hat{J}_{S R}$ provides reasonably acceptable upper bound of the actual one in a wide range of $\omega_{1} / \omega_{G}$. Fig.8 indicates the convergence of $\hat{J}_{S R}$ (Eq.(32c)) with respect to $\omega_{U}$ and the actual one (Eq.(31)) with respect to the upper circular frequency for two cases $\omega_{1} / \omega_{G}=1,5$ in soil type 1 . The actual one in Fig.8 was computed by using 200(rad/s) as the upper circular frequency in Eq.(31) different from that in Fig.7. It can be found that, while $\omega_{U}=2000(\mathrm{rad} / \mathrm{s})$ is preferable from the convergence point of view, $\omega_{U}=200(\mathrm{rad} / \mathrm{s})$ may be used from the viewpoint of computational efficiency within acceptable accuracy.

\subsection{Case of damped surface ground amplification}

Consider second the damped case for the free-field ground amplification. The damping of the surface ground is set to 0.05 . For simplicity the damping of the engineering bedrock is assumed to be the same as that of the surface ground. The soil damping ratio depends on the experienced shear strain amplitude and a well-known SHAKE program can be used. However, since the main purpose of this paper is to provide a new method for evaluating the upper bound of input energy to a building structure on a surface ground, a 
simple case of soil damping ratio 0.05 is assumed. The case of uncertain surface ground damping will be discussed later in this section.

Fig.9 shows an example of the energy transfer function $F_{A}(\omega)$ and an example of the function $\left|H_{G}(\omega)\right|^{2}$. Let $J_{S R}^{U}$ and $\hat{J}_{S R}$ denote the upper bound and the proposed upper bound using a narrower bound of amplification (see Fig.9). Furthermore let $U_{b}$ denote the upper bound of the squared transfer function of the surface ground (see Fig.9). $J_{S R}^{U}$ and $\hat{J}_{S R}$ can be derived as Eq.(32a) and Eq.(32c). As in the case of undamped surface ground amplification, Eq.(32c) enables the evaluation of the upper bound of the scaled earthquake input energy without infinite integration by taking full advantage of Eq.(25).

Fig.10 shows $F_{A}(\omega)$ and $\left|H_{G}(\omega)\right|^{2}$ for the superstructure with the fundamental natural period of $0.525(\mathrm{~s})$ and the damping ratio 0.02 for three soil types 1-3. Fig.11 illustrates $\hat{J}_{S R}$ and the actual one with respect to the ratio of the fundamental natural circular frequency $\omega_{1}$ of the superstructure to the fundamental natural circular frequency $\omega_{G}$ of the surface ground for three soil types 1-3. 200(rad/s) was adopted as $\omega_{U}$ in Eq.(32c) and 5000(rad/s) was employed as the upper circular frequency for computation in Eq.(31). It can be observed that, even if the surface ground property changes, the proposed upper bound of the scaled earthquake input energy $\hat{J}_{S R}$ provides reasonably acceptable upper bound of the actual one in a wide range of $\omega_{1} / \omega_{G}$. Fig.12 indicates the convergence of $\hat{J}_{S R}$ (Eq.(32c)) with respect to $\omega_{U}$ and the actual one (Eq.(31)) with respect to the upper circular frequency for two cases $\omega_{1} / \omega_{G}=1,5$ in soil type 1 . The actual one in Fig.12 was computed by using 200(rad/s) as the upper circular frequency in Eq.(31) different from that in Fig.11. It can be found that, while $\omega_{U}=2000(\mathrm{rad} / \mathrm{s})$ is preferable from the convergence point of view, $\omega_{U}=200(\mathrm{rad} / \mathrm{s})$ may be used from the viewpoint of computational efficiency within acceptable accuracy.

Fig.13 illustrates some examples of envelope functions of $\left|H_{G}(\omega)\right|$ for uncertain shear wave velocity and damping ratio of surface ground. The nominal values are shear wave velocity $=200(\mathrm{~m} / \mathrm{s})$ and damping ratio=0.05. Fig.13(a) is plotted for uncertain shear wave velocity (0.8-1.2 of nominal value), Fig.13(b) is for uncertain damping ratio (0.8-1.2 of nominal value) and Fig.13(c) is for uncertain combinations of shear wave velocity (0.8-1.2 of 
nominal value) and damping ratio (0.8-1.2 of nominal value). Once an envelope function squared $\left|H_{G}(\omega)\right|^{2}$ is specified and its upper bound $U_{b}$ is determined, these can be used as $\left|H_{G}(\omega)\right|^{2}$ and $U_{b}$ in Eq.(32a) and Eq.(32c). Then $J_{S R}^{U}$ and $\hat{J}_{S R}$ in Eq.(32a) and Eq.(32c) can be utilized as the upper bound and the proposed narrower upper bound for uncertain shear wave velocity and damping ratio of surface ground.

\section{Earthquake input energy to substructures in SR model subjected to white-noise-like engineering bedrock input}

Fig.14 shows the scaled earthquake input energies for engineering bedrock input to the overall SR model $J_{S R}$, the superstructure $J_{S}$ and the foundation-soil system $J_{F}$ with respect to $\omega_{1} / \omega_{G}$ for the case of undamped surface soil amplification. These quantities are given by

$$
\begin{aligned}
& J_{S R}=\int_{0}^{\infty} F_{A}(\omega)\left|H_{G}(\omega)\right|^{2} d \omega \\
& J_{S}=\int_{0}^{\infty} F_{S}(\omega)\left|H_{G}(\omega)\right|^{2} d \omega \\
& J_{F}=\int_{0}^{\infty} F_{F}(\omega)\left|H_{G}(\omega)\right|^{2} d \omega
\end{aligned}
$$

As explained in Eq.(31), $J_{S R}, J_{S}$ and $J_{F}$ in Eq.(34a-c) indicate the earthquake input energies to the overall SR model, the superstructure and the foundation-soil system, respectively, subjected to a white-noise-like engineering bedrock input with $\left|\ddot{U}_{g 0}(\omega)\right|=1$. The upper frequency for computation of Eq.(31) is 5000(rad/s) in this case. It can be observed that, as the superstructure becomes stiffer $\left(\omega_{1} / \omega_{G}\right.$ becomes larger), the scaled earthquake input energy concentrates to the foundation-soil system.

Fig.15 illustrates the scaled earthquake input energies for engineering bedrock input to the overall SR model, the superstructure and the foundation-soil system with respect to $\omega_{1} / \omega_{G}$ for the case of damped surface ground amplification. The damping ratio of 0.05 has been adopted. The same tendency as in the undamped case can be observed.

\section{Extension to general ground motion input at engineering bedrock surface}

Consider a general ground motion input at the engineering bedrock surface the Fourier 
amplitude of which is shown in Fig.16. Assume that the upper bound of the squared Fourier amplitude $\left|\ddot{U}_{g 0}(\omega)\right|^{2}$ is given by the following form.

$$
\begin{aligned}
& \left(\left|\ddot{U}_{g 0}(\omega)\right|^{2}\right)^{U}=R_{C}+R_{V}(\omega) \\
& R_{V}(\omega)= \begin{cases}R_{V}(\omega) & \left(0 \leq \omega \leq \omega_{I}\right) \\
0 & \left(\omega_{I} \leq \omega\right)\end{cases}
\end{aligned}
$$

This model implies that most earthquake ground motions at the engineering bedrock surface have a predominant frequency in rather lower frequency range and the components at higher frequencies are bounded by a constant value.

The first upper bound of the earthquake input energy to the SR model under the engineering bedrock horizontal ground acceleration $\ddot{u}_{g 0}$ may be expressed as

$$
\hat{E}_{I}^{A}=\int_{0}^{\infty} F_{A}(\omega)\left|H_{G}(\omega)\right|^{2}\left(\left|\ddot{U}_{g 0}(\omega)\right|^{U}\right)^{2} d \omega
$$

This bound can be proved by $\left|\ddot{U}_{g 0}(\omega)\right|^{2} \leq\left(\left|\ddot{U}_{g 0}(\omega)\right|^{2}\right)^{U}$ and the property of $F_{A}(\omega)$ as a positive function. As shown above, the following relation holds.

$$
J_{S R}^{F}=\int_{0}^{\infty} F_{A}(\omega) d \omega=\frac{1}{2} \sum m_{i}
$$

By taking advantage of Eq.(37), the second upper bound of the earthquake input energy to the SR model under the engineering bedrock horizontal ground acceleration $\ddot{u}_{g 0}$ may be derived as follows.

$$
\begin{aligned}
\hat{E}_{I}^{A}= & \int_{0}^{\infty} F_{A}(\omega)\left\{U_{b}-\left(U_{b}-\left|H_{G}(\omega)\right|^{2}\right)\right\}\left(R_{C}+R_{V}(\omega)\right) d \omega \\
= & \int_{0}^{\infty} F_{A}(\omega)\left\{U_{b} R_{C}+U_{b} R_{V}(\omega)-\left(U_{b}-\left|H_{G}(\omega)\right|^{2}\right) R_{C}-\left(U_{b}-\left|H_{G}(\omega)\right|^{2}\right) R_{V}(\omega)\right\} d \omega \\
\leq & \frac{1}{2} U_{b} R_{C} \sum_{i} m_{i}+U_{b} \int_{0}^{\omega_{I}} F_{A}(\omega) R_{V}(\omega) d \omega \\
& -R_{C} \int_{0}^{\omega_{U}} F_{A}(\omega)\left(U_{b}-\left|H_{G}(\omega)\right|^{2}\right) d \omega-\int_{0}^{\omega_{I}} F_{A}(\omega)\left(U_{b}-\left|H_{G}(\omega)\right|^{2}\right) R_{V}(\omega) d \omega \\
= & \hat{\hat{E}}_{I}^{A}
\end{aligned}
$$

The validity of this second upper bound can be proven by the property of $F_{A}(\omega)$ as a positive function, as explained above, and the round-up of the squared surface soil transfer function 
$\left|H_{G}(\omega)\right|^{2}$ to $U_{b}$ in $\omega_{U} \leq \omega$ (i.e. $\left(U_{b}-\left|H_{G}(\omega)\right|^{2}\right) \rightarrow 0$ in $\left.\omega_{U} \leq \omega\right)$. Eq.(38) shows that the upper bound of input energy can be computed without infinite integration.

The numerical simulation of the theory on upper bound for a general earthquake ground motion model shown in this section will be presented in the future.

Furthermore, only elastic structures have been treated for simple presentation of the theory. Since the present method takes advantage of the energy transfer function approach which can be used for elastic structures, an equivalent linearization technique [25-27] may be promising for inelastic structures. This formulation will also be presented in the future.

\section{Conclusions}

The conclusions may be summarized as follows:

(1) When the ground surface motion is white-like (constant Fourier amplitude spectrum), the input energy to the swaying-rocking model is constant regardless of the soil property, i.e. input energy constant property. This property can be proved by considering the physical meaning of the constant Fourier spectrum of the input ground surface motion in the time domain, i.e. the input of initial velocity at zero time.

(2) A good estimation of the upper bound of earthquake input energy to the swaying-rocking model is derived for the model including the surface ground amplification by taking full advantage of the property stated in the above conclusion (1) and a narrower upper bound of the surface ground amplification (transfer function squared). Numerical examples demonstrated that the proposed upper bound using the narrower upper bound of the surface ground amplification is a reasonable upper bound of the actual one for all soil types 1-3.

(3) The procedure of deriving the upper bound of earthquake input energy to the swayingrocking model stated in conclusion (2) can be applied to the case with uncertain shear wave velocity and damping ratio of the surface ground.

(4) Extension of the theory to a general earthquake ground motion model at the engineering bedrock has also been made by taking full advantage of the above-mentioned input energy constant property and another upper bound of input energy has been derived. The validity 
of that upper bound can be proven by using the property of the energy transfer function as a positive function and the round-up of the squared surface soil transfer function.

\section{Acknowledgements}

Part of the present work is supported by the Grant-in-Aid for Scientific Research of Japan Society for the Promotion of Science (No.24246095). This support is greatly appreciated.

\section{References}

[1] Trifunac, M.D., Hao, T.Y., and Todorovska, M.I, On energy flow in earthquake response, Report CE 01-03, July 2001, Univ. of Southern Calif., 2001.

[2] Trifunac, M.D., Energy of strong motion at earthquake source, Soil Dynamics and Earthquake Engineering, 2008; 28: 1-6.

[3] Takewaki, I., Bound of earthquake input energy to soil-structure interaction systems, Soil Dynamics and Earthquake Engineering, 2005; 25(7-10): 741-752.

[4] Housner, G.W., Behavior of structures during earthquakes. Journal of the Engineering Mechanics Division, ASCE, 1959; 85(4): 109-129.

[5] Berg, G.V., and Thomaides T.T. Energy consumption by structures in strong-motion earthquakes. Proceedings of 2nd World Conf. on Earthquake Engineering, Tokyo and Kyoto, 681-696, 1960.

[6] Housner, G.W. Measures of severity of earthquake ground shaking. Proc. of the US National Conf. on Earthquake Engineering, Ann Arbor, Michigan, 25-33, 1975.

[7] Housner, G.W., and Jennings, P.C. (1975) The capacity of extreme earthquake motions to damage structures. Structural and geotechnical mechanics: A volume honoring N.M.Newmark edited by W.J. Hall, 102-116, Prentice-Hall Englewood Cliff, NJ.

[8] Zahrah, T.F., and Hall, W.J. Earthquake energy absorption in SDOF structures. Journal of Structural Engineering, ASCE, 1984; 110(8): 1757-1772.

[9] Akiyama, H. (1985). Earthquake resistant limit-state design for buildings. University of Tokyo Press, Tokyo, Japan. 
[10] Ohi, K., Takanashi, K., and Tanaka, H. A simple method to estimate the statistical parameters of energy input to structures during earthquakes. Journal of Structural and Construction Eng., Archi. Inst. of Japan, 1985; 347: 47-55 (in Japanese).

[11] Uang, C.M., and Bertero, V.V. Evaluation of seismic energy in structures. Earthquake Engineering and Structural Dynamics, 1990; 19: 77-90.

[12] Leger, P., and Dussault, S. Seismic-energy dissipation in MDOF structures. Journal of Structural Engineering, ASCE, 1992; 118(5): 1251-1269.

[13] Fajfar, P., and Vidic, T., Consistent inelastic design spectra: hysteretic and input energy. Earthquake Engineering and Structural Dynamics, 1994; 23(5): 523-537.

[14] Kuwamura, H., Kirino, Y., and Akiyama, H. Prediction of earthquake energy input from smoothed Fourier amplitude spectrum. Earthquake Engineering and Structural Dynamics, 1994; 23: 1125-1137.

[15] Riddell, R., and Garcia, J.E. Hysteretic energy spectrum and damage control. Earthquake Engineering and Structural Dynamics, 2001; 30: 1791-1816.

[16] Lyon, R.H. Statistical energy analysis of dynamical systems, The MIT Press, Cambridge, MA, 1975.

[17] Ordaz, M., Huerta, B., and Reinoso, E. Exact computation of input-energy spectra from Fourier amplitude spectra, Earthquake Engineering and Structural Dynamics, 2003; 32: 597-605.

[18] Takewaki, I. Bound of Earthquake Input Energy, Journal of Structural Engineering, ASCE, 2004; 130(9): 1289-1297.

[19] Takewaki, I. Frequency domain modal analysis of earthquake input energy to highly damped passive control structures, Earthquake Engineering \& Structural Dynamics, 2004; 33(5): 575-590.

[20] Takewaki, I. Frequency domain analysis of earthquake input energy to structure-pile systems, Engineering Structures, 2005: 27(4), 549-563.

[21] Takewaki, I., and Fujita, K. Earthquake input energy to tall and base-isolated buildings in time and frequency dual domains, J. of The Structural Design of Tall and Special Buildings, 2009; 18(6): 589-606. 
[22] Schnabel, P.B., Lysmer, J. and Seed, H.B. SHAKE: A computer program for earthquake rsponse analysis of horizontally layered sites, A computer program distributed by NISEE/ Computer Applications, Berkeley, 1972.

[23] Kramer, S.L. Geotechnical earthquake engineering, Prentice Hall, 1996.

[24] Parmelee, R.A. The influence of foundation parameters on the seismic response of interaction systems, Proc. of the 3rd Japan Earthquake Engineering Symposium, Vol.3, 49-56, 1970

[25] Caughey, TK. Random excitation of a system with bilinear hysteresis. Journal of Applied Mechanics, 1960; 649-652.

[26] Roberts, JB and Spanos, PD. Random Vibration and Statistical Linearization. Wiley, New York, 1990.

[27] Takewaki, I. Probabilistic critical excitation for MDOF elastic-plastic structures on compliant ground, Earthquake Engineering \& Structural Dynamics, 2001; 30(9): 13451360.

Table 1 Structural and foundation parameters

\begin{tabular}{|c|c|}
\hline & superstructure \\
\hline Fundamental natural period (fixed- base) & $0.525 \mathrm{~s}$ \\
\hline Fundamental natural circular frequency (fixed- base) & $11.97 \mathrm{rad} / \mathrm{s}$ \\
\hline Mass (equivalent mass for lowest mode) & $2.09 \times 10^{5} \mathrm{~kg}$ \\
\hline Mass height (equivalent height for lowest mode) & $12.8 \mathrm{~m}$ \\
\hline Foundation mass & $1.54 \times 10^{5} \mathrm{~kg}$ \\
\hline Damping ratio for superstructure & 0.02 \\
\hline Mass moment of inertia of superstructure & $1.12 \times 10^{6} \mathrm{kgm}^{2}$ \\
\hline Mass moment of inertia of foundation & $0.819 \times 10^{6} \mathrm{kgm}^{2}$ \\
\hline
\end{tabular}




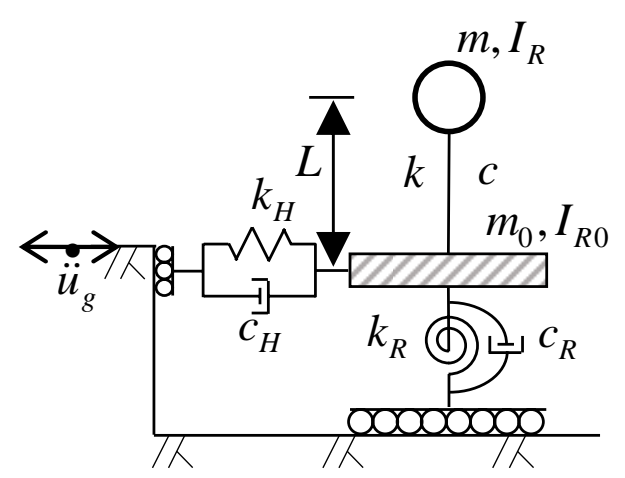

Fig.1 Swaying-rocking model subjected to free-field ground motion

$$
\text { ( } \left.\ddot{y}+\ddot{u}_{g}\right)
$$

Fig.2 Free-body diagram for overall SR model

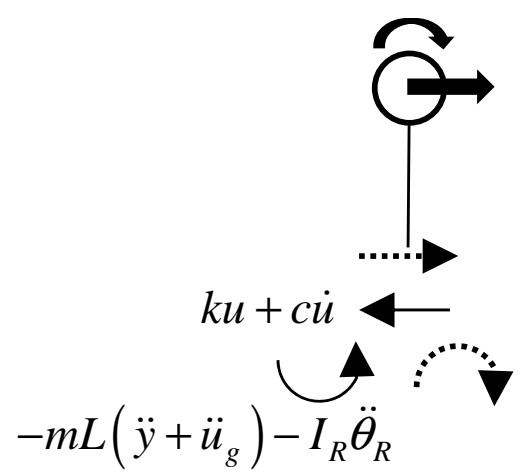

Fig.3 Free-body diagram for superstructure

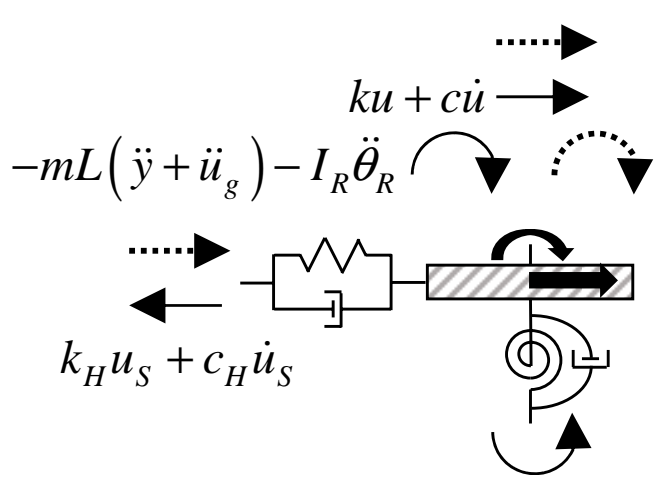

Fig.4 Free-body diagram for foundation-soil system 

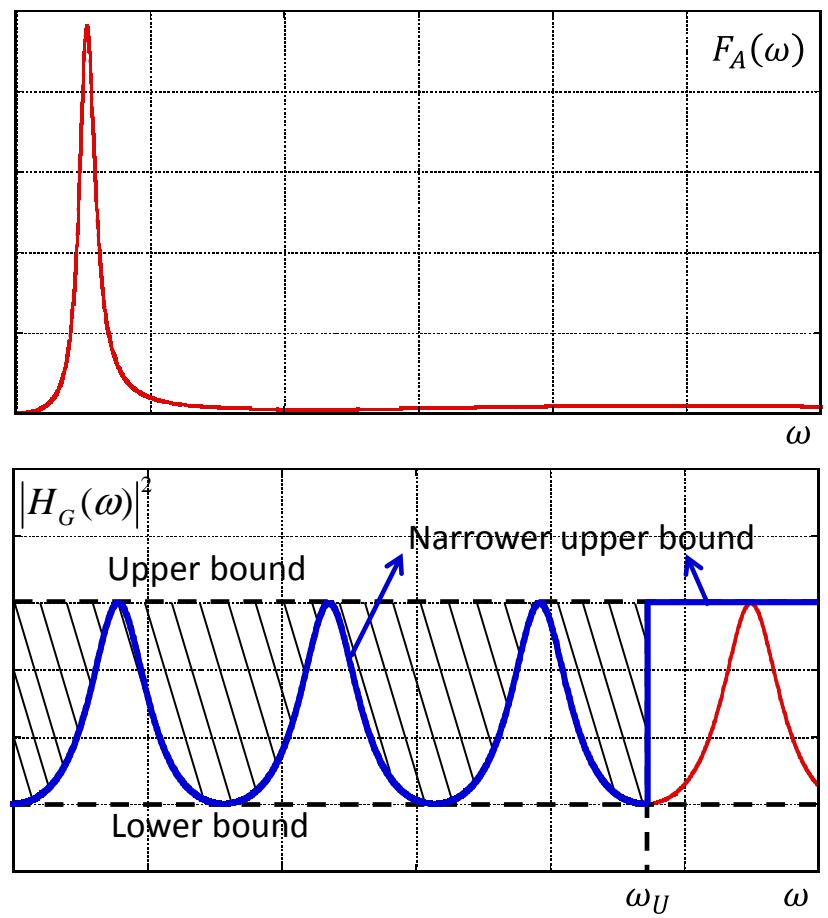

Fig.5 Energy transfer function of SR model and narrower upper bound of surface ground amplification (undamped case for surface-ground amplification)

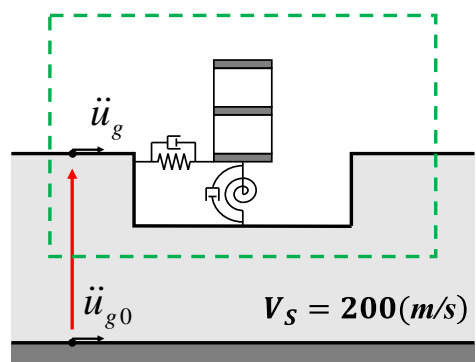

Soil type $1 V_{S}=400(\mathrm{~m} / \mathrm{s})$

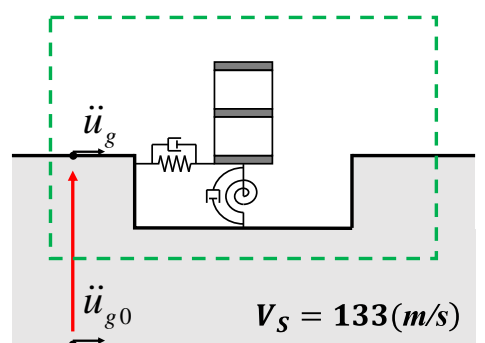

Soil type $2 \quad V_{S}=400(\mathrm{~m} / \mathrm{s})$

Fig.6 Three soil types

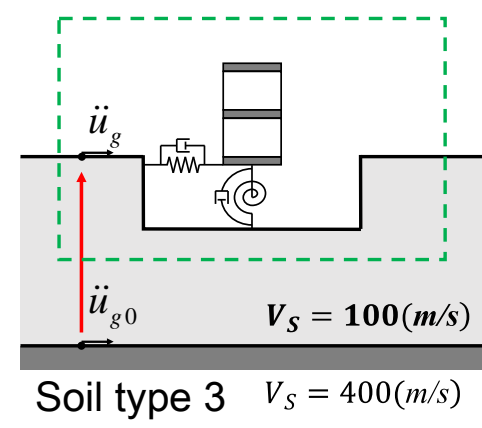

Soil type $3 \quad V_{S}=400(\mathrm{~m} / \mathrm{s})$ 

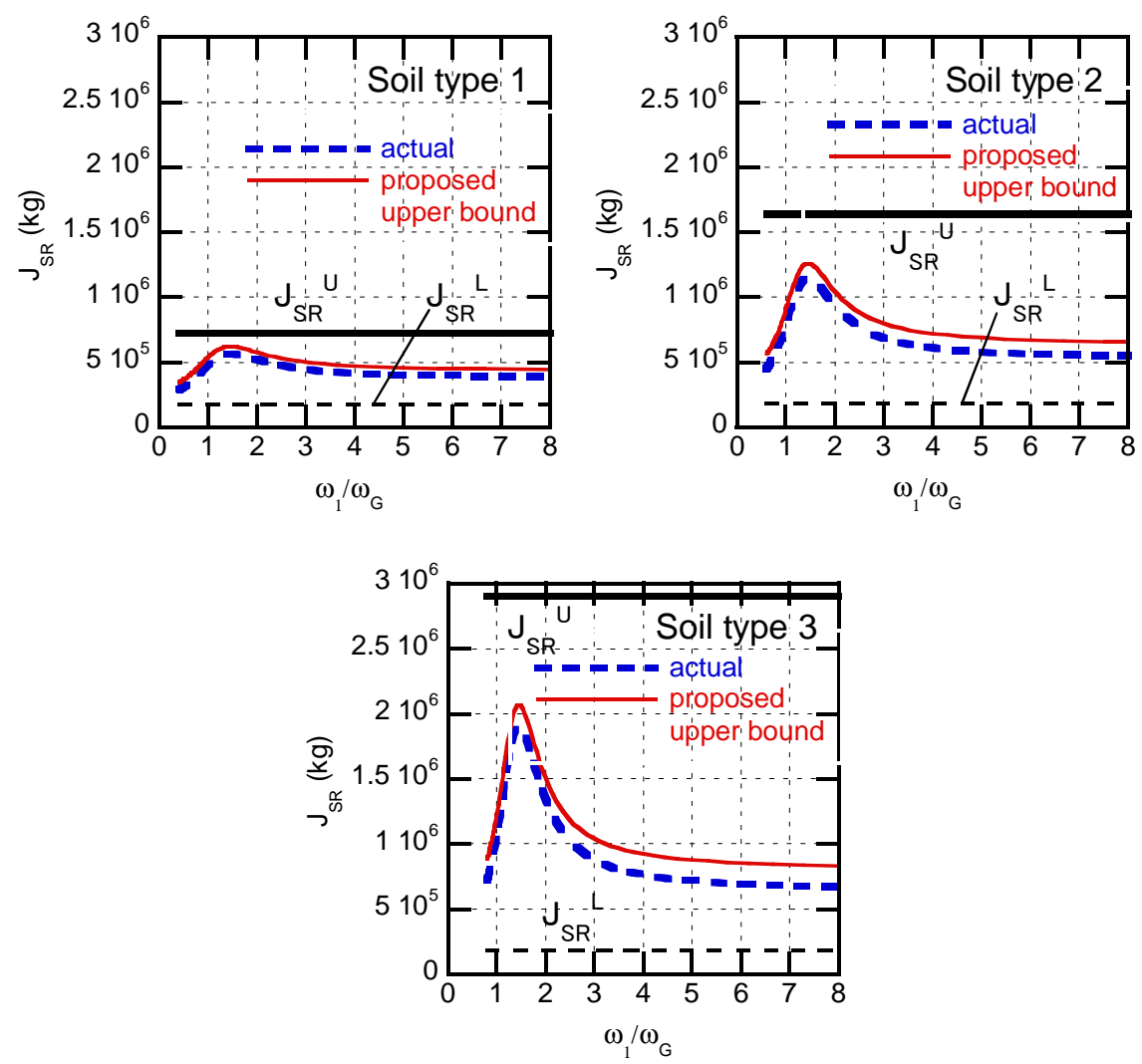

Fig.7 Scaled earthquake input energy to SR model: actual one, upper bound, lower bound and proposed upper bound using narrower bound of amplification (undamped case for amplification)

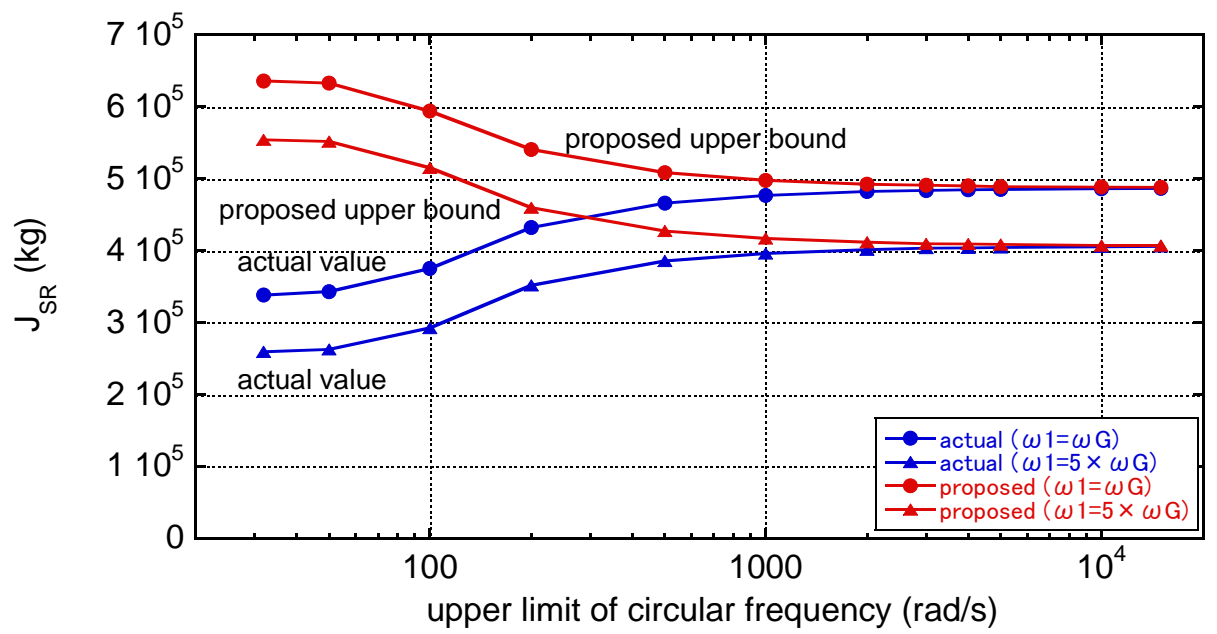

Fig.8 Convergence of scaled earthquake input energy to SR model with respect to upper limit of circular frequency for computation (comparison of proposed upper bound with actual one in case of undamped surface-ground amplification: soil type 1) 

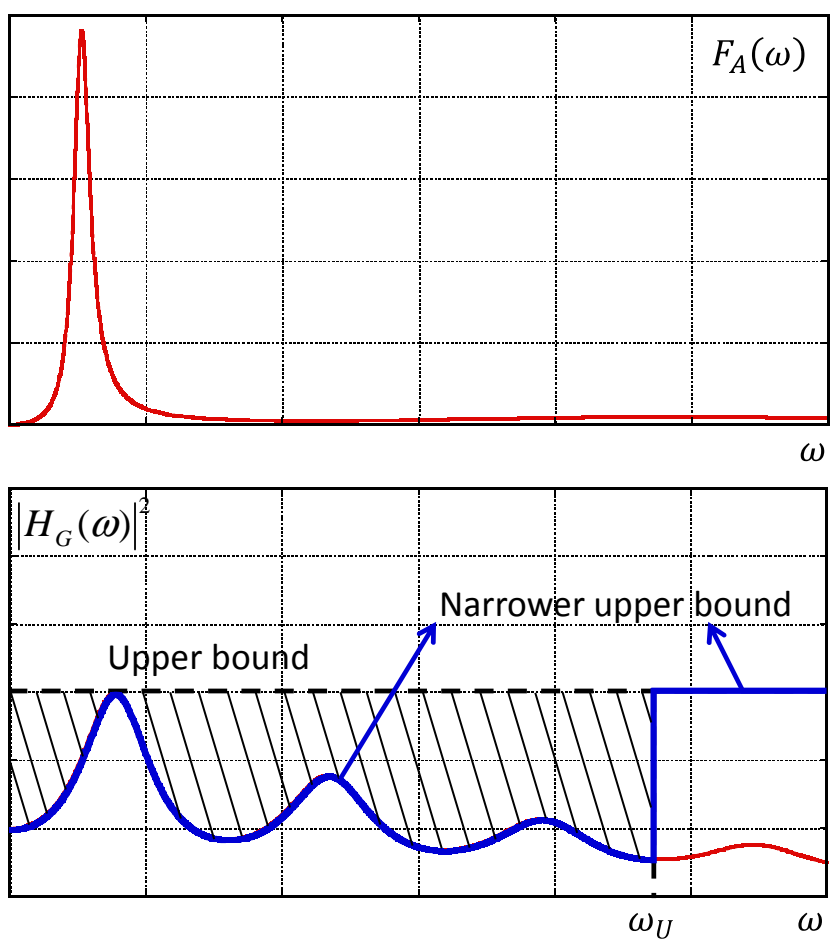

Fig.9 Energy transfer function of SR model and narrower upper bound of surface ground amplification (damped case for surface-ground amplification) 

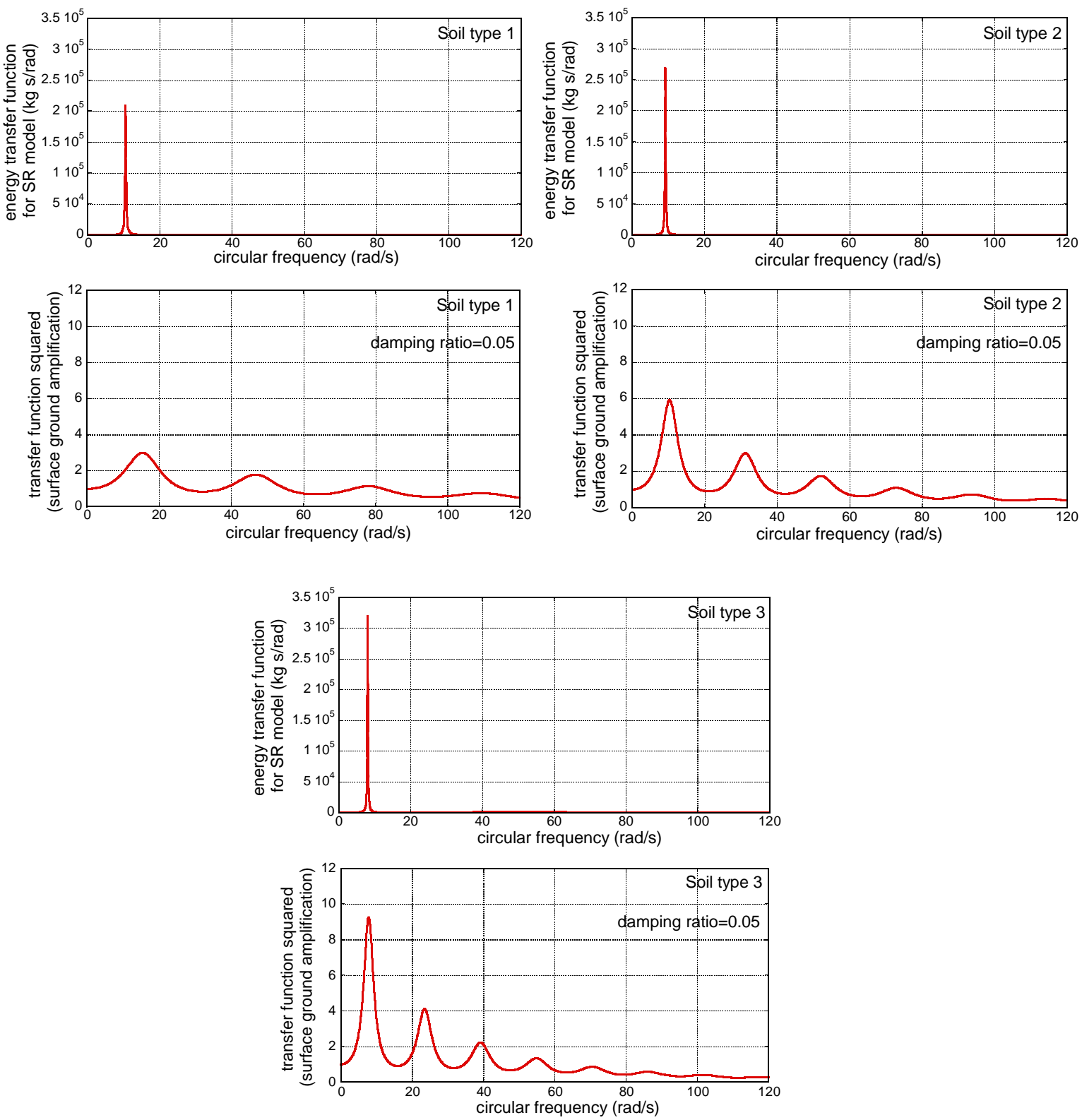

Fig.10 Energy transfer function of SR model and transfer function squared of surface ground for three ground types (damped case for surface-ground amplification) 

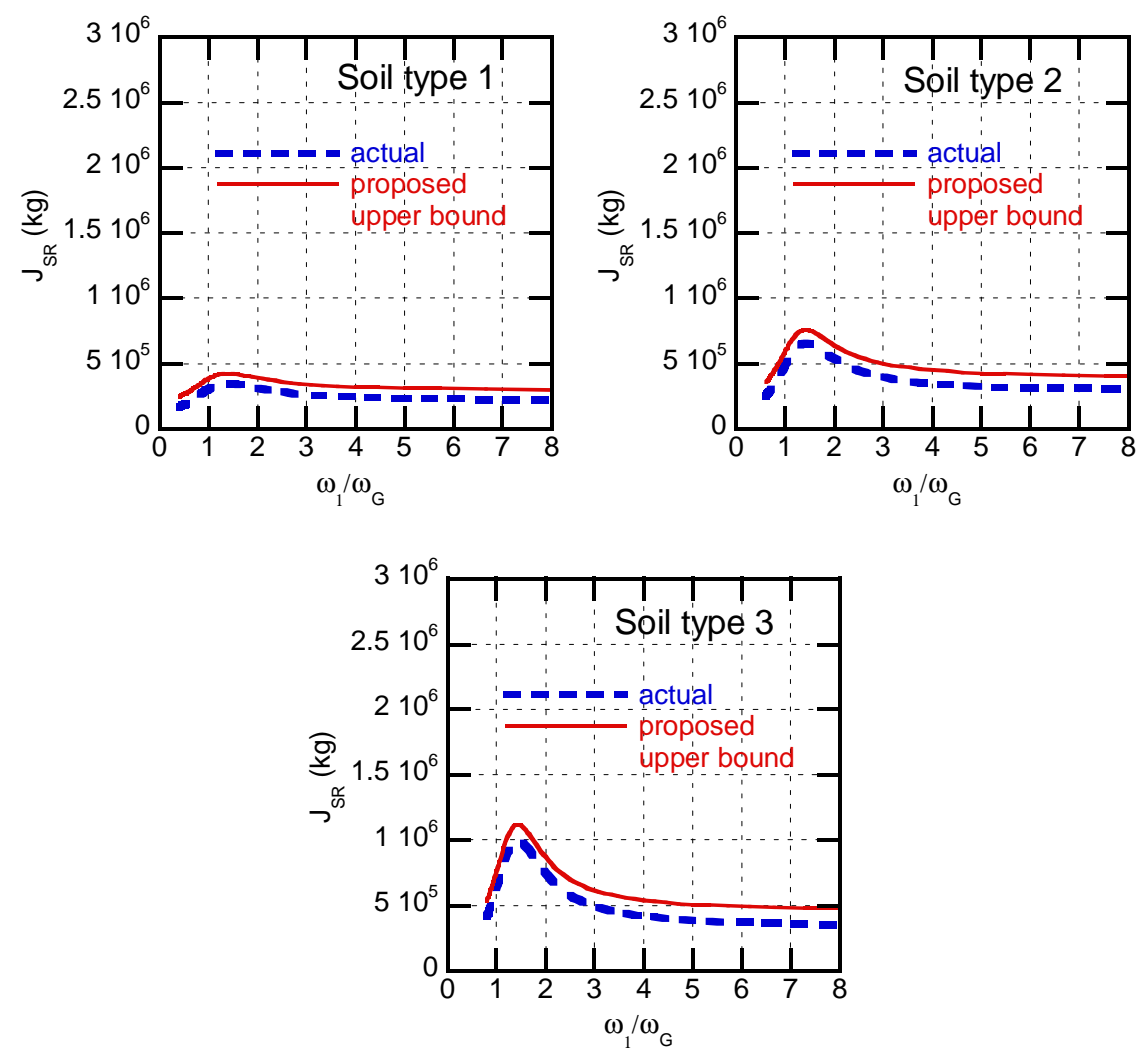

Fig.11 Scaled earthquake input energy to SR model: actual one and proposed upper bound using narrower bound of amplification (damped case for amplification)

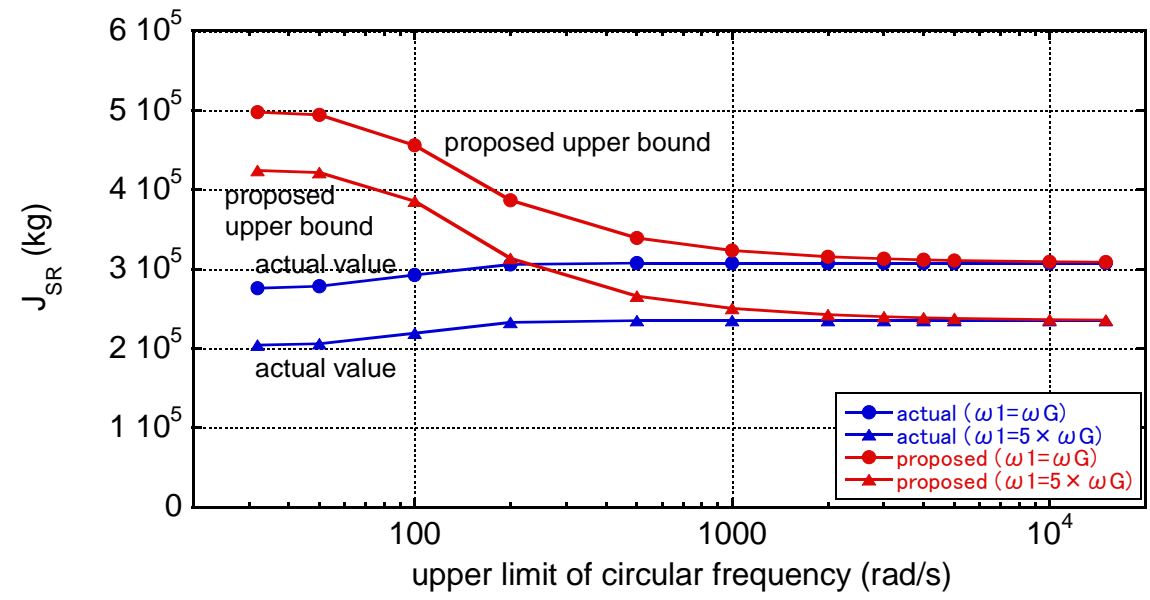

Fig.12 Convergence of scaled earthquake input energy to SR model with respect to upper limit of circular frequency for computation (comparison of proposed upper bound with actual one in case of damped surface-ground amplification: soil type 1) 


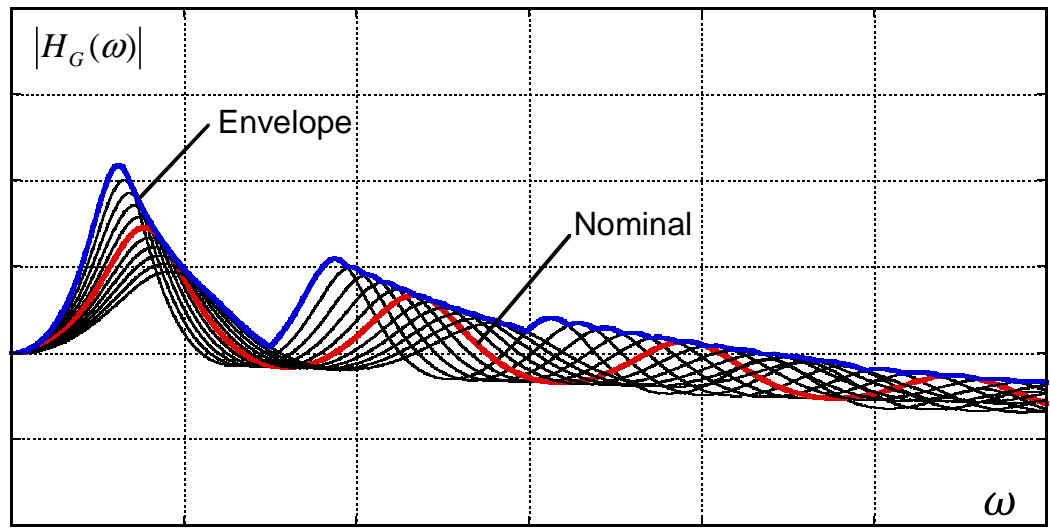

(a) Varied shear wave velocity (0.8-1.2 of nominal value)

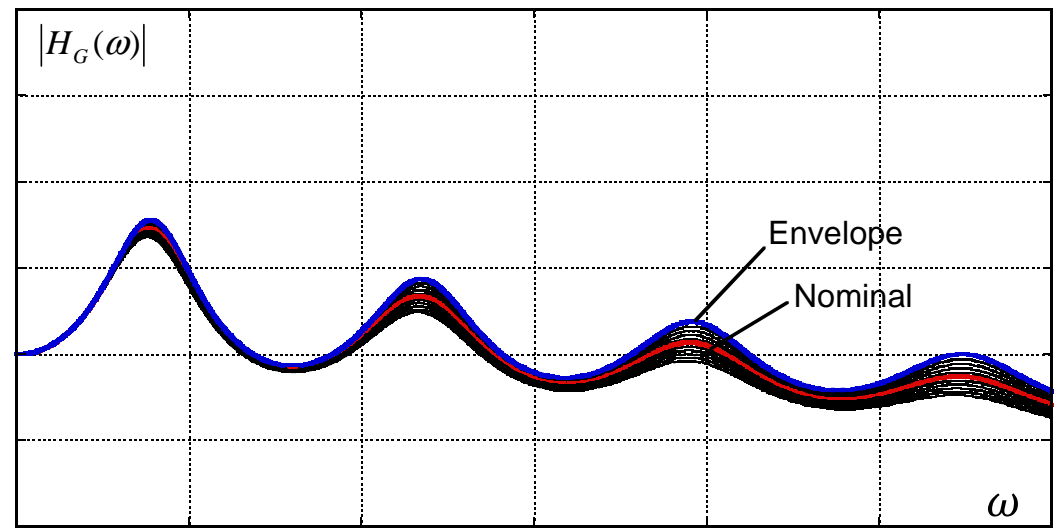

(b) Varied damping ratio (0.8-1.2 of nominal value)

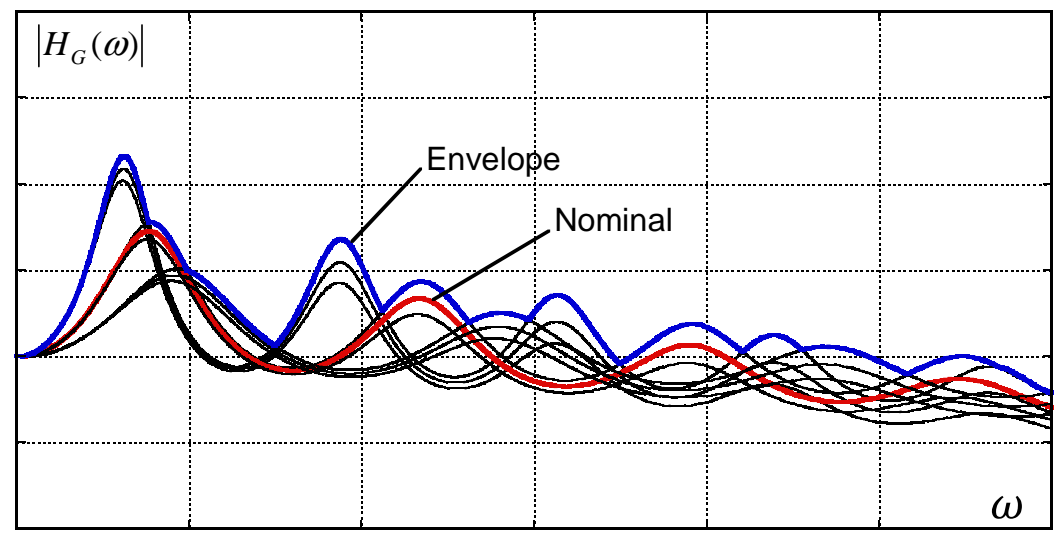

(c) Varied shear wave velocity and damping ratio (0.8-1.2 of nominal value)

Fig.13 Envelope function of $\left|H_{G}(\omega)\right|$ for uncertain shear wave velocity and damping ratio of surface ground 

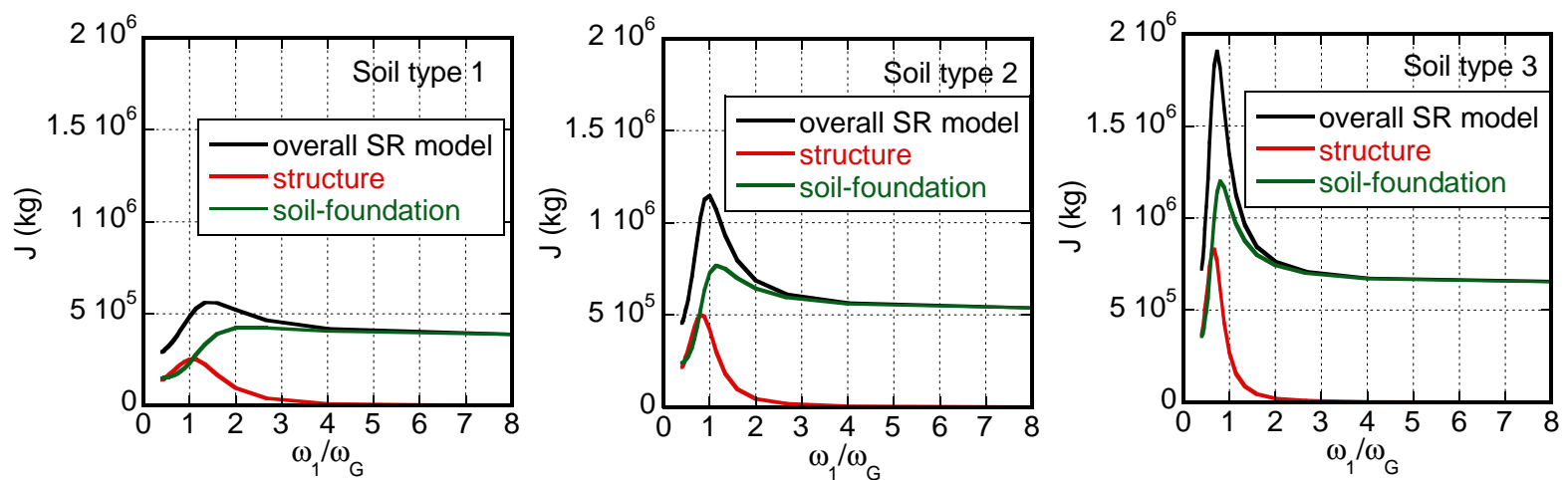

Fig.14 Scaled earthquake input energy to substructures in SR model subjected to white-noiselike engineering bedrock input in case of undamped surface-ground amplification
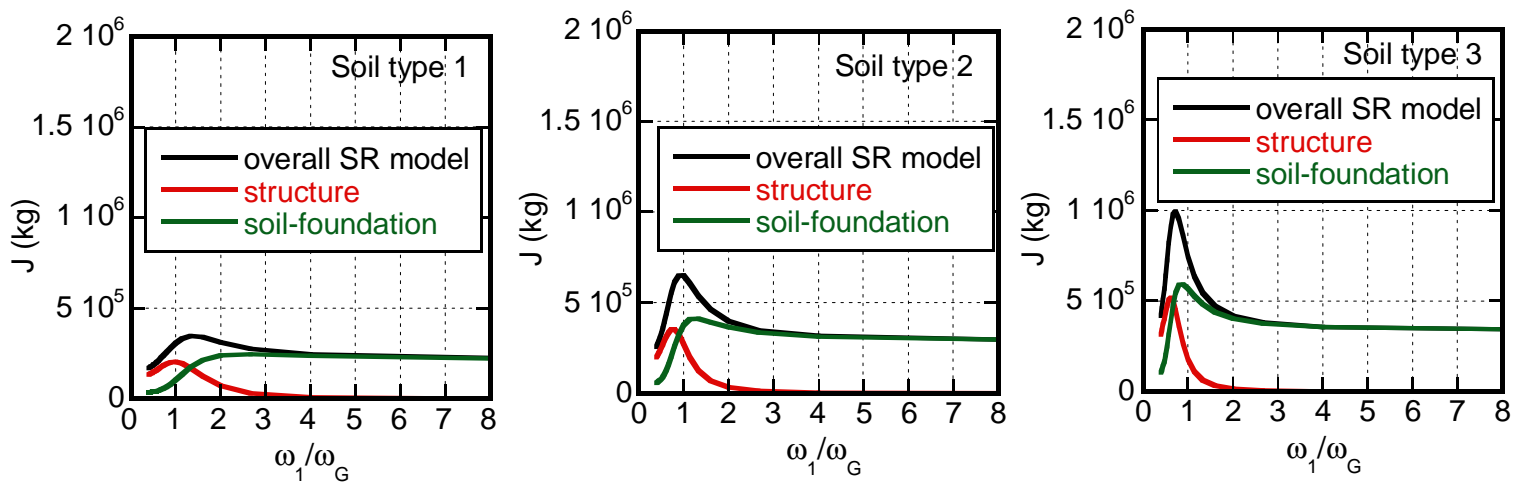

Fig.15 Scaled earthquake input energy to substructures in SR model subjected to white-noiselike engineering bedrock input in case of damped surface-ground amplification
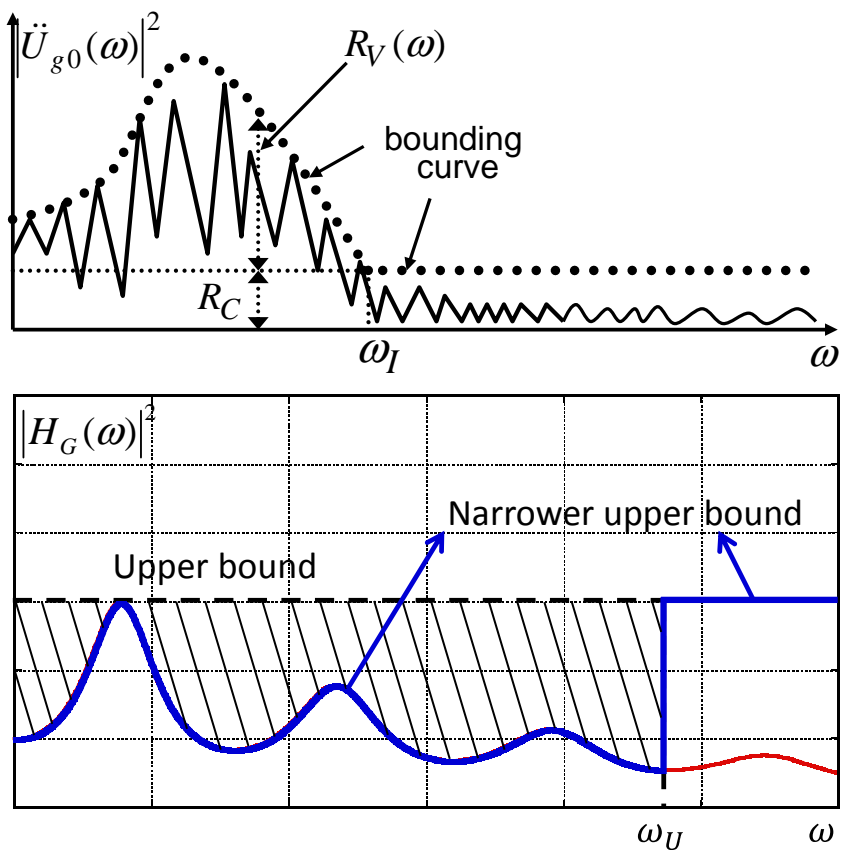

Fig.16 Upper bound model of squared Fourier amplitude of ground motion at engineering bedrock and round-up of squared surface soil transfer function for computation of narrower upper bound of input energy 